\title{
ARTIGOS
}

Recebido em 23.07.2012. Aprovado em 09.10.2012

Avaliado pelo sistema double blind review. Editor Científico Eduardo Davel

\section{GOVERNAMENTALIDADE EMPRESARIAL E SABERES ADM}

\author{
Business governability and ADM know-how \\ Gubernamentalidad empresarial y conocimiento ADM
}

\begin{abstract}
RESUMO
Interessa discutir o modo pelos quais somos governados na atualidade. Um modo que parece operar por meio de determinado tipo de mentalidade que a cada dia ajuda a produzir e difundir modos de conduta. Os saberes ADM, aqueles que circulam no campo da administração, extrapolando-o, participam da produção e disseminação de uma mentalidade empresarial que, por sua vez, está na base da governamentalidade atual. 0 artigo abordará a noção de governo, noção que não se refere somente às estruturas políticas e à gestão do Estado, mas também aos modos de ação sobre as possibilidades de ação de outros. Em seguida, abordará a noção de governamentalidade em diferentes épocas, enfocando na governamentalidade de empresa ou empresarial uma espécie de mentalidade que governa a todos. A partir daí é possível pensar o governo que os saberes do campo da administração exercem na atualidade.
\end{abstract}

PALAVRAS-CHAVE | Governo, Governamentalidade, empresa, saberes, ADM.

\begin{abstract}
It is of interest to discuss how we are currently governed. A way that seems to operate through a given type of mentality every day helps to produce and disseminate means of conduct. ADM know-how, which circulates in the field of administration and extrapolates it, takes part in the production and dissemination of a business mentality which, in turn, is at the basis of current governability. This paper addresses the notion of government, one that does not only refer to political structures and to State management, but also to the means of action over the possibilities of action by others. It then addresses the notion of governability in different times, focusing on company or business governability, a sort of mentality that governs all. Based on that, it is possible for government to think of administration know-how as it is exercised nowadays.
\end{abstract}

KEYWORDS / Government, Governability, company, know-how, ADM.

\section{RESUMEN}

Interesa discutir el modo por el cual somos gobernados en la actualidad. Un modo que parece operar por medio de determinado tipo de mentalidad que a cada día ayuda a producir y difundir modos de conducta. Los conocimientos ADM, aquellos que circulan en el campo de la administración, sobrepasándolo, participan de la producción y diseminación de una mentalidad empresarial que, a su vez, está en la base de la gubernamentalidad actual. El artículo tratará la noción de gobierno, noción que no se refiere solamente a las estructuras políticas y a la gestión del Estado, sino también a los modos de acción sobre las posibilidades de acción de otros. A continuación, tratará la noción de gubernamentalidad en diferentes épocas, con enfoque en la gubernamentalidad de empresa o empresarial, una especie de mentalidad que gobierna a todos. A partir de ello, es posible pensar la influencia que los conocimientos del campo de la administración ejercen en la actualidad.

PALABRAS CLAVE / Gobierno, Gubernamentalidad, empresa, saberes, ADM. 


\section{INTRODUÇÃO}

Os modos pelos quais somos governados atualmente são modelos de conduta pautados nos modos de ação empresariais e que atingem profissionais das mais diferentes áreas, levando -os a seguir certas verdades, a buscar determinados saberes.

Há uma forma empresa em pleno funcionamento que se tornou um modelo de conduta para os indivíduos e para a sociedade, influenciando sobremaneira os modos de vida. Dessa maneira, interessa discutir o modo pelos quais somos governados na atualidade em sua interface com os saberes ADM. Tal maneira de referir-se à área foi inspirada na expressão utilizada em outra área de conhecimento, a psicologia e seus saberes psi.

Os saberes que circulam no campo da administração, extrapolando para outros campos, podem ser percebidos como algo necessário à sobrevivência. Assim, o objetivo desse ensaio é colocar em discussão o modo que governa a todos nós por meio dos saberes do campo da administração, estimulando outros estudos e demonstrando que essa questão precisa ser alvo da atenção daqueles que são administradores, daqueles que formam administradores e daqueles que trabalham com gestão.

Esse modo parece operar por meio de um tipo de mentalidade, de maneira que todos consomem uma forma empresa, com seus valores, que passam a produzir e disseminar modos de conduta. Uma mentalidade que opera por meio de mecanismos de poder.

Esses mecanismos de poder procuram assujeitar os indivíduos por determinadas verdades que são percebidas como possibilidades de salvação (MOTTA e ALCADIPANI, 2004). Ao mesmo tempo, aqueles que buscam tais conhecimentos, por vezes, encontram-se voltados para a busca de soluções, de tendências e modelos. Uma procura que contribui para a propagação e o consumo de técnicas e teorias consideradas verdades.

A discussão abordará primeiramente a noção de governo e em seguida a noção de governamentalidade. A partir daí será possível pensar sobre o governo que os saberes do campo da administração exercem na atualidade.

\section{DA NOÇÃO DE GOVERNO}

A partir dos estudos de Foucault (1984), vemos que no Econômico de Xenofonte (1999), da Grécia clássica, havia um conjunto de preceitos relativos à maneira de governar o próprio patrimônio, conselhos que serviriam para administrar seus domínios, dirigir os trabalhadores, aplicar boas técnicas, vender ou comprar. O objetivo era manter e desenvolver o patrimônio em um processo de reflexão sobre os meios para atingir esse objetivo, ou seja, uma reflexão sobre a arte de comandar.

Nesse tempo, ser casado significava ser chefe de família, ter uma autoridade e exercer um poder que tinha a casa como o seu local de aplicação e ter certas obrigações que tinham efeitos na reputação do cidadão. 0 casamento e a boa conduta do marido eram vinculados a uma reflexão sobre o oikos, isto é, a uma preocupação com a maneira de conduzir a casa e de se conduzir como chefe dessa casa.

O oikos, fora a casa propriamente dita, também era constituído pelas terras e pelos bens, definindo uma esfera de atividades ligadas a um estilo de vida. Tais atividades eram úteis a toda a cidade porque contribuíam para a riqueza e a prosperidade e forneciam bons defensores para a cidade, que eram os proprietários de terras.

Comandar a casa não era uma prática considerada diferente do poder que era exercido no âmbito da cidade. A arte doméstica era considerada de forma semelhante à arte política ou à arte militar no que se trata de governar. Também é preciso considerar que o governo da cidade pressupunha um bom governo, ou seja, uma gestão adequada dos negócios, da casa, da família, dos bens, da esposa e dos escravos.

Nessa época, o domínio de si que precisava ser feito pelo cidadão, esse governo de si mesmo, era uma espécie de condição moral para poder dirigir os outros. Tal condição moral significava buscar ser exemplar, um modelo, algo que traria certa distinção em relação aos demais. O governo, como indica Foucault (2008a), de uma prática do âmbito familiar e de uma prática no âmbito da cidade passou por um processo de disseminação por todo o arcabouço estatal.

Dois processos ocorreram: enquanto o modelo da família já não era possível para pensar aspectos relacionados à população, como no caso das epidemias, por exemplo, o governo dos bens, da mulher, dos filhos e dos criados, encarado como uma prática doméstica, foi adentrando e se expandindo no aparelhamento do Estado por meio de práticas de gestão. Ou seja, as práticas de gestão foram disseminando-se, pouco a pouco, e ainda hoje se encontram em pleno funcionamento nos diferentes âmbitos: individual, familiar, no Estado e em todo o tecido social.

Importante lembrar que governo nem sempre significou algo ligado ao Estado. Antes de a palavra adquirir tal significado, que começou a tomar forma entre os séculos XVI e XVII, ela sofreu alguns deslocamentos. De acordo com dicionários históricos da língua francesa, a palavra "governar" antes tinha o sentido espacial de dirigir, de fazer ir em frente ou o sentido de seguir um caminho ou fazer alguém seguir esse caminho. Um sentido mais abrangente era o de sustentar-se assegurando a 
subsistência (trigo suficiente para governar Paris por dois anos) ou no sentido de tirar subsistência de alguma coisa (uma cidade que se governa de seus tecidos) (FOUCAULT, 2008b).

No entanto, a noção de governo também comportaria o sentido de conduzir alguém, no sentido espiritual, também significando a imposição de um regime, como um médico impõe a um paciente. A palavra governar ou o governo pode referir-se à conduta no sentido moral (uma mulher que é de mau governo) e também pode se referir a uma relação entre indivíduos, como em uma relação de chefia, como dirigir alguém ou controlá-lo. Também pode ser uma relação verbal, falar com alguém, entreter essa pessoa ou, ainda, um controle que pode ser exercido sobre si mesmo e sobre os outros, sobre o corpo e sobre os modos de agir.

Quando o governo se referia ao controle exercido sobre si mesmo, existiam indagações sobre quais regras adotar para si, a fim de se conduzir como convém, de como se conduzir na vida em relação aos outros e em relação às autoridades, uma preocupação voltada à conduta (FOUCAULT, 2008a).

Governo, aqui, é entendido como mecanismos e procedimentos voltados para a condução dos homens, ou seja, voltados para a direção das suas condutas. Contudo, o governo dos homens é uma prática que não é imposta dos governantes para os governados. De acordo com Foucault (2008b), é uma prática que fixa a posição de ambos, uns diante dos outros e em relação aos outros.

Interessa a esta discussão justamente essa noção ampliada de que governo não se refere somente às estruturas políticas e à gestão do Estado, ou mesmo às formas instituídas no âmbito econômico ou político, mas principalmente aos modos de ação sobre as possibilidades de ação de outros. Isso porque nas organizações, nas relações estabelecidas na sociedade entre indivíduos, entre grupos, entre organizações e as múltiplas facetas do Estado, cada um lida com as prescrições comportamentais em vigor, pois se percebem obrigados a obedecê-las.

\section{GOVERNAMENTALIDADE}

A partir dos escritos de Foucault (2008a; 2008b; 2010b), acerca das práticas de governo, a ideia de governamentalidade ajuda a pensar nos modos pelos quais somos governados atualmente por meio dos saberes ADM. Enquanto alguns preferem falar de uma governamentalidade neoliberal, nomeia-se aqui a governamentalidade atual de governamentalidade de empresa ou governamentalidade empresarial.

Os modos pelos quais somos governados são modelos de conduta pautados nos modos de ação empresariais que atingem profissionais das mais diferentes áreas, levando-nos a buscar certos saberes. Essa mentalidade que nos governa direciona nossos modos de viver, num processo cotidiano de naturalização de saberes e da forma empresa. Saberes disseminados, em parte, via formação em administração, bem como via MBAs, capacitações, cursos de finais de semana e literatura gerencial. Saberes que operam disseminando e reforçando uma mentalidade que atua no governo dos indivíduos.

Como Motta (1994) bem observou, sendo a nossa sociedade, uma sociedade de organizações, as condutas são aprendidas em meio a uma lógica da organização. Além de produzirem bens tangiveis e intangíveis, elas produzem modos de se comportar e pensar.

O termo governamentalidade procura chamar a atenção para certa maneira de pensar e agir, incorporada nos esforços para conhecer e governar a riqueza, a saúde e a felicidade das populações (ROSE e MILLER, 1992). Governamentalidade não está dicionarizada na língua portuguesa e significa qualidade ou modo de ser daquilo que é governamental, daquilo que pertence e é parte ou é relativo ao governo (Foucault, 2008a; Veiga-Neto, 2005).

O conceito de governamentalidade é profícuo, na medida em que sinaliza como as técnicas voltadas ao governo de si mesmo são inseparáveis dos mecanismos de poder. Também indica como o governo utiliza livremente as estratégias desenvolvidas pelos próprios governados, usadas como mecanismos de poder sobre estes. Mas a resistência cria espaços de liberdade, que não só restabelecem o equilíbrio entre governantes e governados, mas também permitem que estes últimos escapem, pelo menos momentaneamente, do alcance das técnicas voltadas ao governo de si mesmo (Dalgliesh, 2009).

Governamentalidade, governar (governare) e mentalidade (mentalitê), de acordo com Lemke (2000), enfatiza uma interdependência entre o exercício do governamento, ou seja, práticas, e a mentalidade que sustenta tais práticas. Governamentalidade seria um esforço para criar sujeitos governáveis por meio de técnicas que controlam e moldam condutas.

Quais técnicas estariam hoje controlando e moldando as condutas? Que modos de vida estariam sendo valorizados e intensamente buscados? Modos de vida que se encontram gerenciados e técnicas de gestão que invadem praticamente todas as dimensões da vida.

Vimos até aqui a noção de governo e a noção de governamentalidade. Foucault (2008a; 2008b), ao tratar do processo de governamentalização do Estado, partiu da discussão do poder pastoral, um modelo precursor das artes de governar. Além desse modelo, analisou três formas históricas de governamen- 
talidade, chamadas, respectivamente, de a razão de Estado, o liberalismo e o neoliberalismo (ALCADIPANI, 2005).

0 poder pastoral começou a ser organizado no oriente pré-cristão e depois cristão. Inicialmente, era exercido sobre uma multiplicidade em movimento e não sobre um território. Tinha por objetivo a salvação do rebanho, ou seja, os meios de subsistência. Com isso, o homem ocidental aprendeu o que os gregos jamais admitiriam, isto é, a se considerar uma ovelha entre ovelhas. 0 poder pastoral deu lugar a uma arte de conduzir, dirigir, guiar e controlar os homens ao longo da vida coletiva e individualmente. Esse seria um pano de fundo histórico do processo que leva à formação de uma governamentalidade. 0 pastorado teria se dispersado, por meio de regras de conduta, até tomar uma dimensão de governo (FOUCAULT, 2008a).

A técnica do poder pastoral procura criar indivíduos subjugados e sujeitos dentro de um dado regime de verdade (ALCADIPANI, 2005; Foucault, 2010a). Procura produzir também o modo como estes lidam com o regime de verdade de seu tempo, isto é, como cada vida lida com certos conjuntos de regras em vigor naquele momento histórico, os modos pelos quais os sujeitos se percebem obrigados a cumpri-los e como se reconhecem ligados a eles. 0 que o indivíduo fará diante da obrigação de agir de tal maneira, em função de tal preceito moral (FONSECA, 2007).

Nesse sentido, de que maneira os indivíduos vêm lidando com o regime de verdade de seu tempo? Como cada um lida com as prescrições que procuram direcionar, inclusive o que devem ou não aprender para permanecerem empregáveis?

Um regime de verdade é aquilo que constrange os indivíduos a atos de verdade. A obrigação de realizar certas coisas e de dizer aquilo que é considerado verdadeiro (FOUCAULT, 2010b).

Além do poder pastoral, também é importante tratarmos das três formas históricas de governamentalidade, para visualizarmos os deslocamentos que ocorreram até a sua configuração contemporânea e podermos, em seguida, colocar em discussão a mentalidade que nos governa em sua interface com os saberes da administração.

A razão de Estado foi a primeira forma moderna da arte de governar, uma forma política de poder que foi se desenvolvendo desde o século XVI, e que permitiu a ampliação do poder pastoral para além da instituição eclesiástica, ampliando-se por todo o tecido social, apoiando-se em instituições que o exerciam de modo individualizante: empregadores, medicina, psiquiatria, educação e família (ALCADIPANI, 2005; FOUCAULT, 2010a).

O governo passava por alguns níveis: o governo do Estado, referido à política, o governo da família, à economia, e o governo de si mesmo, à moral. Governamentalidade seria o resultado do processo pelo qual um Estado de justiça da Idade
Média nos séculos XV e XVI foi tornando-se um Estado administrativo, isto é, o Estado foi sendo governamentalizado, tornando-se uma sociedade com regulamentos (FOUCAULT, 2008b). Aqui, o Estado não é considerado uma instância dada e acabada. As ações governamentais distribuídas na sociedade são muito mais práticas do que uma instância governamental e administrativa. É muito mais uma ação de governar que no sentido arcaico (do latim gubernare, derivado do grego kubernan) significava executar a ação de conduzir ou dirigir ações alheias (VEIGA-NETO, 2005).

Além disso, ocorreram deslocamentos entre o chamado sistema de polícia, no sentido entendido no século XVII e início do século XVIII, e o sistema embasado na economia.

No sistema de polícia, havia uma preocupação com a quantidade populacional quanto à necessidade de mais pessoas para trabalhar, ao refreamento dos aumentos salariais, à garantia de preços de custo mínimos para as coisas fabricadas e comercializadas. No sistema da economia acreditava-se que não era preciso haver uma população tão volumosa a ponto de os salários tornarem-se baixos demais para que conseguissem consumir e sustentar os preços. No sistema de polícia, procurava-se mandar para outros países tudo que fosse possível de mercadorias para extrair o máximo de ouro, enquanto no sistema da economia havia novas técnicas que buscavam integrar os países estrangeiros a mecanismos de regulação, deixando a concorrência entre os particulares agir, procurando o lucro máximo (FOUCAULT, 2008b, 2010b).

A nova forma de governamentalidade sofreu uma espécie de limitação, tendo em vista que a intervenção do Estado sobre a vida e as atividades das pessoas foi contida. "O instrumento da transformação foi a economia política e o seu resultado foi uma nova governamentalidade, denominada liberalismo" (ALCADIPANI, 2005, p. 101).

Houve uma substituição de uma regulamentação mediante a autoridade de polícia por uma regulamentação a partir do curso das próprias coisas, em que um preço justo deveria manter relação com o trabalho realizado, com as necessidades dos comerciantes e as possibilidades dos consumidores. O bem de todos não dependia mais da intervenção autoritária do Estado, com regulamentações sob a forma de polícia, população e território; agora, o bem de todos estaria assegurado por meio do comportamento de cada um. O Estado passa a ser um regulador de interesses, esboçando uma nova forma de governamentalidade não mais na razão de Estado, mas, sim, em um novo domínio que estava se configurando, a economia (FOUCAULT, 2008a).

Ainda conforme Foucault (2008a), no século XIX havia a ideia de que se a arte de governar estava ligada à descoberta de 
uma verdade e ao seu conhecimento objetivo, isso implicaria a constituição de um saber especializado e de uma categoria de indivíduos especializados. Certo número de indivíduos passou a se apresentar como especialistas de uma verdade que deveria ser imposta numa articulação entre um regime de obrigação e de constrangimento particular, um regime de verdade.

Outra forma de governamentalidade seria o neoliberalismo, surgido na Alemanha como uma crítica ao nazismo e ao processo de reconstrução do Estado alemão no pós-guerra. Uma liberdade econômica que assegura ao Estado, concomitantemente, sua existência e sua limitação (ALCADIPANI, 2005; FOUCAULT, 2008b). Já o neoliberalismo americano estava imbricado com a política do New Deal, um plano econômico que controlava os investimentos na indústria, a política de emprego e a emissão de valores monetários. Se no liberalismo o Estado não deveria interferir na economia, garantindo a livre iniciativa, com a nova doutrina (FOUCAULT, 2008b) o Estado passou a atuar diretamente na economia.

Atualmente, o poder político é exercido em meio a uma profusão de alianças entre diversas autoridades em projetos e instâncias para governar uma multiplicidade de aspectos da atividade econômica, da vida social e das condutas individuais. 0 poder está mais para algo que produz cidadãos capazes de suportar um tipo de liberdade regulada do que para um mecanismo que impõe restrições (ROSE, MILLER, 1992).

Alcadipani (2005) lembra que uma das características do neoliberalismo norte-americano foi a demarcação da análise comportamental como sendo uma das tarefas da economia, preocupando-se com o modo pelo qual se produz e o modo pelo qual se acumula o capital denominado humano. Com isso, a economia de mercado passou a ser utilizada para compreender as relações que não eram (e ainda não são) propriamente de mercado, num processo de generalização do modo de funcionamento do mercado no campo social.

Somos governados por saberes de diferentes campos do conhecimento. Contudo, após vermos as formas históricas de governamentalidade até a sua configuração atual, trataremos da mentalidade que nos governa em sua interface com os saberes do campo da administração.

\section{DO GOVERNO DOS SABERES ADM}

Essa generalização do modo de funcionamento do mercado, esse modelo empresarial passa pela produção de normas gerais de conduta em sociedade, um modo que imprime estilos de vida e maneiras de se conduzir. Um processo que incentiva a busca e utilização de determinados saberes.
Ao tratar do consumo de saberes e estilos de vida na atualidade, Chiappini (2008) diz que todos nós consumimos a empresa todos os dias, no momento em que consumimos técnicas de gestão e estilos de vida que são gerenciais e ao mesmo tempo gerenciados. Contudo, aqueles que lidam com os saberes ADM vivenciam mais intensamente esse modo de governo.

Antes de tornar-se um profissional, um estudante já tem acesso a algumas prescrições comportamentais, recebendo esquemas e recomendações, certos modelos que propõem maneiras de se conduzir em certas situações, perante pessoas e em relação aos conhecimentos que deve adquirir.

Segue o exemplo de publicação voltada para aqueles que ainda estão definindo o curso de exame vestibular (Série Profissões, 2006, p. 47), na qual há mandamentos voltados ao futuro estudante de administração, tais como:

Antes de mais nada, escolha uma faculdade bem conceituada, capaz de tornar mais fácil o acesso ao mercado.

Continue estudando após a conclusão da graduação. Faça um MBA ou pós-graduação no Brasil ou no exterior, pois o mercado valoriza os profissionais que têm essas extensões no currículo.

Aprenda a ouvir e a ter jogo de cintura para trabalhar em equipe.

Deixe de lado a timidez e exerça todo o seu talento em liderança. Provavelmente, em breve, você terá que enfrentar o desafio de dirigir equipes, habilidade muito valorizada na profissão.

Esses mandamentos para os futuros estudantes são orientações comportamentais, uma direção das condutas, um modo de incitar práticas. Após acessarem tais orientações, aqueles que escolhem o curso de administração acreditam que podem segui-las. Não são apenas esquemas valorizados, recomendados e até impostos; são escolhas em relação aos modos de se conduzir em meio a regras e prescrições estabelecidas.

São práticas, procedimentos que são pressupostos ou prescritos aos indivíduos para fixar sua identidade, para mantê -la ou transformá-la em função de determinados fins, "o governo de si por si na sua articulação com as relações com o outro (como é encontrado na pedagogia, nos conselhos de conduta, na direção espiritual, na prescrição de modelos de vida etc.)" (FOUCAULT, 1997, p.111).

Nesse sentido, os mandamentos para os vestibulandos são prescrições comportamentais encontradas na literatura gerencial, muitas vezes percebidas como possibilidades de salvação. Nesse contexto, para a maioria populacional, salvação seria não ser descartado do mercado de trabalho, seria governar a si mesmo em meio à governamentalidade atual, de modo a manter-se empregável. 
Foucault (2003, p. 200) falou em textos práticos: "textos que pretendem estabelecer regras, dar opiniões, conselhos de como se conduzir de modo adequado". Esses textos seriam também objeto de prática, uma vez que exigem ser lidos, apreendidos, visando constituir um arcabouço da conduta.

As teorias da área não instigam certas práticas, não disseminam saberes considerados verdades? Para Tragtenberg (2006), o próprio discurso da chamada teoria geral da administração muda em função das determinações sociais, pois saberes considerados verdades são práticas e estão imbricados com as relações de poder existentes em um momento histórico, remetendo ao modo como os homens se governam por meio da produção de verdade.

Quando se ouve um aluno de graduação falar: "estou aqui para aprender técnicas de gestão e só" ou "empresa é feita pra dar lucro, o resto é conversa”, precisamos parar e pensar sobre isso e em que tipo de profissionais e cidadãos estamos formando nas instituições de ensino. A gestão teria somente a dimensão técnica? E a dimensão política? E a social? A finalidade das organizações é diferente da consequência de seu desempenho.

Outro ponto é que fora os administradores, profissionais de outras áreas também se encontram imersos nessa mentalidade, participando de sua disseminação, incluindo-se aí nós, professores e pesquisadores da área de administração.

Aqueles que trabalham em organizações e estão vinculados de tal modo ao seu trabalho e à organização foram chamados de homem organização. Pessoas que trabalham e que também pertencem à organização, que fizeram votos para uma vida nela. O homem organização seria um funcionário-executivo-subordinado. O seminarista que terminará por encabeçar a hierarquia eclesiástica, o médico que estará à frente de uma clínica particular, o intelectual que trabalha em um projeto de uma fundação, o engenheiro que trabalha em uma companhia, um aprendiz de um escritório de advogados de Wall Street. Todos seriam irmãos de sangue do especialista em administração de negócios (WHYTE JR, 1961).

De Grazia (1960) já sinalizava que a administração manifesta características marcantes que fazem parte da ação das pessoas, como nas ordens, nas regras de um superintendente escolar, nas rotinas de um funcionário, na disciplina de um chefe político e em outras atividades humanas. Faz parte da ação humana fazer gestão.

Portanto, muitos fazem gestão, e gerir não é prerrogativa daqueles formados em cursos superiores de administração. Afinal, os saberes da área são buscados também por outros profissionais que também fazem gestão. De acordo com Chandler (1998), a disseminação de práticas de gestão ocorreu com a expansão das especialidades nas profissões, de modo que os de- mais trabalhadores executavam tarefas rotineiras e os profissionais liberais ocupavam cargos de chefia.

Podemos dizer que os indivíduos são investidores na medida em que escolhem em qual empresa investir suas capacidades. Eles são proprietários de um capital humano, considerados uma espécie de ativo, um trabalhador-investidor (LÓPEZ-RUIZ, 2007). As capacidades são percebidas como um tipo de capital, constituindo um estoque que aumentaria as perspectivas de ganho. Com isso, há um processo de captura e conversão dos inúmeros descaminhos pelos quais uma vida poderia passar para uma estratégia de capitalização pessoal num processo de empresariamento da vida (Ambrózio, 2011). Ou seja, as vidas são constantemente direcionadas por uma mentalidade empresarial.

Essa formalização da sociedade baseada no modelo da empresa vem estabelecendo, desde o século XIX, uma sociedade empresarial. 0 homem economicus não é mais o homem da troca, ele é o homem da empresa (Foucault, 2008a). A palavra "empresa" hoje designa uma maneira de se conduzir, empreender qualquer coisa, uma aventura possível para qualquer um, em meio a uma mentalidade na qual cada um é impulsionado a se governar por si mesmo (EHRENBERG, 2010). Sendo assim, a empresa extrapola a empresa, e o cotidiano passa a ser a sua cena, servindo de modelo e de modo de trabalho. De acordo com o autor, isso torna compreensível a imagem do homem que se governa sozinho, o empresário de sua vida.

Essa mentalidade não exprime apenas normas gerais de conduta em sociedade, mas também modos de ação concretos que lidam com problemas, um conjunto de técnicas de gestão que buscam suscitar atitudes de adesão e implicação. Segundo Lorau (1990), esta seria uma versão utilitarista da noção de implicação e que produz juízos de valor: aquela pessoa se implica, aquela outra não se implica o suficiente.

A direção acaba sendo transformada por práticas que levam as pessoas a fazer por si mesmas, sob o efeito de uma decisão voluntária. Um governo também exercido por nós mesmos. E, como disse Foucault (2010b), a racionalidade do governado não é um resultado espontâneo de processos que escapam ao exercício do poder, é preciso que tal racionalidade tenha sido suscitada em relação a uma obediência. Sendo assim, há uma obediência a certas regras de conduta que orientam sobremaneira a buscar e utilizar os saberes ADM como uma condição para conseguir trabalho ou emprego e permanecer neste.

\section{CONCLUSÕES}

Em meio à governamentalidade de empresa, existem os cursos de administração, responsáveis por parte do processo de for- 
mação de milhares de pessoas que, juntamente a uma indústria conexa, reproduzem essa mentalidade. Ao mesmo tempo, devido à existência dessa governamentalidade e da expansão da forma empresa é que essa indústria da gestão se torna a cada dia possível.

Por isso, é necessário colocar em discussão os modos pelos quais somos governados na atualidade, ou seja, a mentalidade que governa em sua interface com os saberes ADM, tendo em vista que sua disseminação contribui para a produção dos modos de vida competitivos, que valorizam o consumo, o acúmulo de alguns bens e o descarte de outros, modos despreocupados com o que estamos fazendo de nós mesmos e do mundo no qual vivemos.

Motta e Alcadipani (2004) já haviam apontado alguns desdobramentos possíveis para o estudo da governamentalidade na análise organizacional.

“A governamentalidade poderia ser de grande valia para a discussão das dinâmicas de governo de organizações e dos instrumentos e mecanismos utilizados para fazer a condução de todos e de cada indivíduo ao mesmo tempo [...]." E prosseguem: “A governamentalidade seria pertinente para analisar os mecanismos de poder que assujeitam os indivíduos por discursos de verdade específicos e que vendem, de forma clara ou velada, a possibilidade de salvação" (MOTTA e ALCADIPANI, 2004, p.126).

A partir disso, propõe-se como estudos futuros, analisar o processo de formação de administradores, investigando de que modos a governamentalidade atual opera desde o curso de graduação, o processo de instituição de modelos e incitação de práticas, com prescrições comportamentais, como lidam com o governo de si mesmos, e o porquê de os administradores serem constituídos tendencialmente de determinado modo. Também é relevante analisar os saberes verdade que são produzidos incessantemente na área, demonstrando que são produções provisórias e que não são universais.

Mas, para tal empreitada, o pensamento de Foucault e dos demais autores não seria usado como mero arcabouço conceitual aplicado a um objeto de pesquisa, e sim como uma ferramenta para o enfrentamento de um problema, provocando intervenções no campo de conhecimento.

Espera-se que essa discussão sobre a mentalidade que nos governa e sua relação com os saberes do campo da administração reverbere e produza mais estudos e outras práticas organizacionais.

Os saberes ADM podem contribuir para o processo de formação de indivíduos (administradores e demais gestores) que buscam simplesmente ser conformes às solicitações organizacionais. Mas também podem contribuir para a formação de indivíduos que repensam modos de funcionamento e tecnologias organizacionais e suas implicações em suas vidas, na sociedade e no planeta.

\section{REFERÊNCIAS}

ALCADIPANI, R. Michel Foucault: poder e análise das organizações. Rio de Janeiro: FGV, 2005.

AMBRÓZIO, A. Empresariamento da vida: discurso gerencialista e processos de subjetivação. 2011. Tese de Doutorado em Psicologia Clínica da Pontifícia Universidade Católica de São Paulo, São Paulo, 2011.

CHANDLER, A. D. Os primórdios da "grande empresa" na indústria norte-americana. In: MCCRAW, T. K. (Org.) Alfred Chandler: ensaios para uma teoria histórica da grande empresa. Rio de Janeiro: FGV, 1998, p. 35-66.

CHIAPPINI, P. Cartografias da empresa: práticas empresariais e produção de subjetividade. 2008. Dissertação de Mestrado pelo Programa de Pós-Graduação em Psicologia Social da Universidade do Estado do Rio de Janeiro, Rio de Janeiro, 2008.

DALGLIESH, B. Foucault and creative resistance in organizations. Society and Business Review. v. 4, n. 1, p. 45-57, 2009.

De GRAZIA, A. The science and values of administration - I. Administrative Science Quarterly. v. 5, n. 3, p. 362-397, 1960.

EHRENBERG, A. $O$ culto da performance: da aventura empreendedora à depressão nervosa. Aparecida, São Paulo: Ideias \& Letras, 2010.

FONSECA, M. A. Michel Foucault e a constituição do sujeito. São Paulo: EDUC, 2007.

FOUCAULT, M. História da sexualidade 2: 0 uso dos prazeres. 4. ed. Rio de Janeiro: Graal, 1984.

FOUCAULT, M. Subjetividade e Verdade. In: Resumo dos cursos do Collège de France (1970 - 1982). Rio de Janeiro: Jorge Zahar, 1997.

FOUCAULT, M. Prisões e revoltas nas prisões. In: MOTTA, M. B. da. Ditos \& Escritos IV. Estratégia, poder-saber. Rio de Janeiro: Forense Universitária, 2003.

FOUCAULT, M. Segurança, território, população. São Paulo: Martins Fontes, 2008a.

FOUCAULT, M. O nascimento da Biopolítica. São Paulo: Martins Fontes, 2008b.

FOUCAULT, M. O sujeito e o poder. In: DREYFUS, H.; RABINOW, P. Michel Foucault: uma trajetória filosófica: para além do estruturalismo e da hermenêutica. 2. ed. Rio de Janeiro: Forense Universitária, $2010 a$.

FOUCAULT, M. O governo de si e dos outros. São Paulo: WMF Martins Fontes, 2010b.

LEMKE, T. Foucault, governamentality and critique. Paper presented at the Rethinkhing Marxism Conference, University of Amherst MA, 21-24 September 2000. Disponivel em: http://www.thomaslemkeweb.de/ publikationen. Acesso em: 24.09.2011.

LÓPEZ-RUIZ, O. J. Os executivos das transnacionais e o espírito do capitalismo: capital humano e empreendedorismo como valores sociais. Rio de Janeiro: Azougue, 2007. 
LOURAU, R. Implication et surimplicacion. Revue du MAUSS - Mouvement Anti-Utilitariste dans les Sciences Sociales, n. 10, 1990.

MOTTA, F. C. P. O que é burocracia. São Paulo: Brasiliense, 1994.

MOTTA, F. C. P; ALCADIPANI, R. O pensamento de Michel Foucault na teoria das organizações. Rausp - Revista de Administração, São Paulo, v. 39, n. 2, p.117-128, 2004.

ROSE, N.; MILLER, P. Political Power beyond the State: Problematics of Government, British Journal of Sociology, v. 43, n. 2, p. 173-205, 1992.

SÉRIE Profissões. São Paulo: Publifolha, 2006.
TRAGTENBERG, M. Burocracia e ideologia. 2. ed. São Paulo: Editora UNESP, 2006.

VEIGA-NETO, A. Coisas do governo... In: RAGO, M.; ORLANDI, L. B. L.; VEIGA-NETO, A. (Orgs.). Imagens de Foucault e Deleuze: ressonâncias nietzchianas. 2. ed. Rio de Janeiro: DP\&A, 2005.

WHITE Jr., W. H. El hombre organización. México: Fondo de Cultura Econômica, 1961.

XENOFONTE. Econômico. São Paulo: Martins Fontes, 1999. 